\title{
Conceptual design of the liquid metal laboratory of the TECHNOFUSION facility
}

\author{
A. Abánades A. García N. Casal J.M. Perlado A. Ibarra
}

\begin{abstract}
A B S T R A C T
The application of liquid metal technology in fusion devices requires R\&D related to many phenomena: interaction between liquid metals and structural material as corrosion, erosion and passivation techniques; magneto-hydrodynamics; free surface fluid-dynamics and any other physical aspect that will be needed for their safe reliable operation. In particular, there is a significant shortage of experimental facilities dedicated to the development of the lithium technology. In the framework of the TECHNOFUSION project, an experimental laboratory devoted to the lithium technology development is proposed, in order to shed some light in the path to IFMIF and the design of chamber's first wall and divertors. The conceptual design foresee a development in two stages, the first one consisting on a material testing loop. The second stage proposes the construction of a mock-up of the IFMIF target that will allow to assess the behaviour of a free-surface lithium target under vacuum conditions. In this paper, such conceptual design is addressed.
\end{abstract}

\section{Introduction}

The development of thermonuclear fusion is one of the most important technological challenges for the scientific, engineering community, not only for the milestone related to the birth of a new energy production system, but also for the impressive amount of scientist, engineers, industries, and economical resources that are involved in a world collaborative project, comparable to others significant projects as the description of human genome.

The practical international collaboration is focused in the design and construction of huge and complex facilities, as ITER and DEMO in the quest for a fusion device, or IFMIF for technological support. Fusion technology is in the edge of the human knowledge for many engineering aspects due to the extreme conditions in which many materials and systems should work. This is true in the case of many common materials, as stainless steels or materials for the solenoids of the confinement magnets. As an example, a huge effort is also in progress to understand, simulate and develop structural materials that could hand the radiation damage and activation that will occur in the first chamber wall. But this assessment is more evident in less common materials, that in many cases become critical for their important role, as it is the case of the liquid metals.

The construction of a prototype of an industrial fusion device from its proven physical principles is an apparent small step on the desk, but a large jump from the technological point of view. The large amount of resources involved in projects as the above mentioned requires the successful development of projects related to technological issues related to several aspects: materials, design tools, magnetohydrodynamics, liquid metal technology, and so on. The mastering of the technology will have a significant effect in the operation and safety of the future fusion devices and imply a reduction of the technological and economical risks of projected demos and prototypes that will be very intensive in cost. There is a certain amount of facilities devoted to fusion technology development. In this paper, the conceptual design of the liquid metal laboratory of the TECHNOFUSION project will be presented with the description of the projected loop, conceived according to a very clear objectives in the context of the worldwide and European roadmap for the magnetic fusion development.

\section{TECHNOFUSION}

As it was cited in the previous section, it is proposed to build a relevant set of facilities in Madrid, Spain, providing new tools to the Fusion Energy community. Such project has been initiated in the framework of an agreement between the regional government of Madrid and the Spanish Science and Innovation Ministry, with CIEMAT and UPM as main technical responsible of the consortium, but with the commitment to serve as booster for the participation of other universities, technological centres and engineering companies interested in the development of fusion technology. Although that is a Spanish initiative, the main objective of TECHNOFUSION is to contribute to the international effort towards Nuclear Fusion 
Energy Fast-Track with the inclusion of different facilities available for international collaboration in the field. Such facilities address horizontal technologies that could be of interest in other scientific areas, creating worthy synergies in the energy field. In particular, that is the case of liquid metals, that are planned to be used in Accelerator Driven Systems for transmutation of nuclear wastes, or Generation IV reactors [1-3].

TECHNOFUSION activities are focused on technological issues, as the radiation effects on structural and functional materials using simultaneous ions and electron accelerators, evaluation of plasma interactions with first wall materials, development of advanced manufacturing technologies and corresponding materials characterization, improvement of liquid metal technologies, or computer simulation and robotics and automation for Remote Handling (RH) including under irradiation operation.

The set of facilities that are now in the phase of conceptual design are linked to the technological objectives of TECHNOFUSION, being the following:

- Material production laboratory.

- Irradiation facilities (proton, electron) [4].

- Material characterization laboratory.

- Plasma-wall interaction laboratory.

- Simulation laboratory [5].

- Liquid metal technology laboratory.

- Remote handling system laboratory [6].

\section{Objectives of the liquid metal laboratory}

Liquid metals are very interesting fluids for fusion applications because of their neutronic and thermo-physical properties. The utilization of liquid metals in fusion technology has been proposed because Tritium production is done trough neutron capture in lithium, which is a liquid metal, and its good properties as coolant material, in opposition to molten salts as flibe, that has good magneto-hydrodynamic properties but poor as coolant due to its high Prandtl number [7]. Therefore, lithium itself is also a good candidate for the design of fusion components, but its design window for the neutron economy of a self-sustained D-T fusion reactor is very narrow and is practically dismissed as blanket material. Then, the eutectic Lead lithium alloy is proposed as candidate material for the Tritium breeding blanket.

In fusion technology development, IFMIF is the reference installation for material testing [16] where neutrons for activation are produced by deuterons impinging a lithium target. The thermalhydraulic description of this liquid metal target is very challenging in the present state of the art of CFD simulation due to the approach that should be done to problems like free surface modelling, added to the description of thermal and velocity boundary layers and heat generation with liquid metals. There is international work in progress to assess the thermal-hydraulic behaviour of this lithium target [17] where the need of CFD code validation was shown to determine turbulence model choice and near wall function treatment.

The state of the art of the liquid metal technology and their future development, particularly in relation with fusion, demands the construction of new infrastructures that could be devoted to the research in several topics as:

- Technological related issues of paramount importance for a practical design and implementation of liquid metal fusion devices in the field of material compatibility, magneto-hydrodynamics, engineering tool validation, component integration, and so on.

- Training of scientists and engineers for an industrial development of liquid metal technology in the fusion field.
- Knowledge and technology transfer among research centres and facilities, universities and industry to establish competent human teams for the deployment of future fusion devices.

In the framework of this project, an analysis of the available experimental facilities devoted to liquid metal technology development has been done, arriving to the conclusion that there is a limited availability of lithium loops to cover the expected demand of experimental data, for instance, required for the IFMIF construction and safe operation.

\section{The liquid metal laboratory of TECHNOFUSION in the international fusion program}

The research and development related to liquid metal application in fusion is supported by a set of facilities that should provide experimental data and technological information to achieve the design and safe construction of fusion devices.

The set of available facilities included the PICOLO loop at Karlsruhe devoted to the material compatibility and corrosion between liquid metals as $\mathrm{Pb}-15.7 \mathrm{Bi}$ with structural materials, including permeation and corrosion barriers $[22,23]$, as well as the DRAGON-I facility in China [24] and the IPUL loop in Latvia. The technological aspects related to liquid metal application in fusion devices are covered, for instance, by the LIFUS facility [25] in which safety related experiments are running, mainly water ingression in liquid metal flows. The technological research is also complemented by component behavior tests that can be done with gas $(\mathrm{He}) / \mathrm{Pb}-\mathrm{Li}$ in facilities as the DIADEMO in France [26] and the EBBTF [10]. Tritium diffusion and transport in $\mathrm{Pb}-\mathrm{Li}$ eutectic is another critical issue that is studied in the TRIEX [27] in which Tritium extraction techniques are developed.

Most of this infrastructure is devoted to the development of technology related to the $\mathrm{Pb}-15.7 \mathrm{Li}$ application to fusion devices. On the other hand, lithium is proposed as material for fusion devices as well. It can be considered a back-up option in the conceptual design of Tritium Blanket Modules (TBM) [28], that are mainly designed with $\mathrm{Pb}-\mathrm{Li}$, but it constitutes a fundamental issue in the case of the IFMIF design [16]. The amount of available facilities devoted to the lithium technology development is very limited, with very low redundancy between them to check the reproducibility of the results, and even a lack of experimental capacity to analyse certain phenomena.

Among the available facilities, the LIMITS [29] installation in the United States is devoted to the analysis of magneto-hydrodynamic effects lithium flows trough system components. The installation LIFUS 3[30] was commissioned in 2008 to study erosion/corrosion phenomena between lithium and structural materials as the AISI 316 or Eurofer 97. The lithium behaviour in presence of gases at different temperatures and Li removal and cleaning was evaluated at LIFUS 3 as well.

The experimental facility at the University of Illinois [31,32] is a reference installation in the analysis of deuterium retention in liquid lithium, what is specially relevant for the application of this liquid metal in the first wall of the plasma chamber of future fusion devices. Regarding specifically to the IFMIF design, the lithium loop at the Osaka University [33] related to the experimental understanding of the free surface phenomena in a liquid lithium loop, is one of the most interesting facilities available worldwide.

In TECHNOFUSION, the design of the experimental facilities that are envisaged is motivated by a technological objective and the foreseen demand from the national and international community. As it has been highlighted, there is a significant shortage of experimental facilities dedicated to the development of the lithium technology for fusion applications. Such fact lead us to propose an 
experimental laboratory devoted to the lithium technology development, in order to shed some light in the path to IFMIF and the design of chamber's first wall and divertors.

\section{Conceptual design of the laboratory}

The liquid lithium laboratory that is proposed for the TECHNOFUSION complex will have as main objective to provide useful scientific information in technological fields as:

- Analysis of free-surface instabilities under vacuum conditions and under irradiation.

- Analysis of liquid lithium interaction with proposed fusion materials as steels (Eurofer, graphite, Be, etc.).

- Magneto-hydrodynamic experiments.

- Test of auxiliary systems as tritium extraction or liquid metal purification.

Regarding lithium and material compatibility analysis, we are working to obtain flow liquid metal velocities up to $20 \mathrm{~m} / \mathrm{s}$ and temperatures up to $1000^{\circ} \mathrm{C}$, that could be used to obtain data for the application of lithium as fusion reactor material in which such very demanding requirements could be met. The design of the material testing loop is in progress and up to now we have not achieved to propose a safe material configuration of the loop at the target temperature, but a dedicated research project has been initiated to assess the technological viability of a lithium loop operating at $1000^{\circ} \mathrm{C}$. Ferritic steels and their compatibility with lithium flows are also analysed in the framework of the LIFE and HYLIFE [21] project at Lawrence Livermore National Laboratory, as one of the most representative inertial fusion programs.

Nevertheless, a first analysis of the structural material for the liquid metal loop is summarized in Table 1. The ferritic and martensitic steels are widely used in the available liquid metal loops, as they are able to operate at temperatures below $600^{\circ} \mathrm{C}$. The development of ODS (Oxide Dispersion Steels) could open the possibility to increase that temperature with low activation [34]. This fact could be interesting for our liquid metal loop, in which some interaction with particle beams are envisaged, but they are still quite far to achieve temperatures of the order of $1000^{\circ} \mathrm{C}$.

The Vanadium alloys will not be able to operate at the targeted temperatures, as they have a temperature limit of $700^{\circ} \mathrm{C}$ on their application with liquid metals $[35,36]$. Some improvements are needed for such alloys regarding welding, as it is needed for refractary materials as tungsten, niobium, tantalum, beryllium [37] and their alloys, that could be selected as a structural material for the liquid metal loop, but with high cost.

Other candidate is silicon carbide (SiC) [38], although its integrity at temperatures in the range that is proposed for our loop must be investigated. There is some work already done regarding $\mathrm{Pb}$ - Li compatibility with $\mathrm{SiC}$ [39], but its application to lithium flows has been scarcely investigated. In fact, the laboratory could be a good facility for such purpose.

Table 1

Maximum temperature of applicability of structural materials for liquid metal technology regarding lithium and eutectic lead lithium.

\begin{tabular}{lrl}
\hline Temperatures $\left({ }^{\circ} \mathrm{C}\right)$ & \multicolumn{1}{c}{$\mathrm{Li}$} & $\mathrm{Pb}-\mathrm{Li}$ \\
\hline Ferritic/martensitic steel & 600 & 450 \\
Vanadium alloys & 700 & 650 \\
Niobium alloys & 1300 & 600 \\
Tantalum alloys & 1370 & 600 \\
Molybdenum & 1370 & 600 \\
Tungsten & 1370 & 600 \\
SiC & 550 & 800 \\
\hline
\end{tabular}

One if the most relevant reasons for the proposal of this liquid metal laboratory is the need for an international facility that could be able to contribute to the complete understanding of the IFMIF target thermal-hydraulics. In that sense, in our conceptual design we planned to install a lithium loop with a scale mock-up of the IFMIF target in which the flow velocities, temperatures and turbulence could be comparable with the foreseen IFMIF target. This mock-up will include the interaction with an electron beam in a curve-shaped target, in which the behaviour of a lithium flow with energy deposition and under practical vacuum at their free surface could be analysed. The foreseen specifications for the free surface are an absolute pressure of $1 \mathrm{mPa}$, as requested for a particle beam tube, and temperatures of the order of $250^{\circ} \mathrm{C}$.

The loops in the laboratory will be used to test and develop liquid lithium purification systems, magneto-hydrodynamics by the potential commissioning of magnets at the loop, and develop some test under electron or photon irradiation.

The development of the laboratory is envisaged in two phases. The first phase will develop the basic infrastructure of the lithium loop, what will allow making same experiments related to material properties or fluid-mechanics validation. The second step will address the required upgrading for free-surface experiments with heat deposition, what would imply the fulfilment of more strict safety and legal normative and administrative reporting to the nuclear regulatory body due to the need of external radiation.

Nevertheless, this approach in two steps reduces the technological risk and implies a lower financial cost, and increases the technological expertise and know-how of the project partners. On the other hand, the regulatory normative concerning lithium inventory and other nuclear issues derived from particle interaction is strongly reduced, what implies a faster construction time schedule.

One of the main objectives of the laboratory is the laboratory is the technology transfer to the engineering companies. To achieve success in that aim, companies as Empresarios Agrupados and IDOM has been involved on the conceptual design of the laboratory and the liquid metal loop in particular.

\section{Experimental facilities}

\subsection{Material testing loop}

A material testing Li loop is proposed for the firs step of the development of the laboratory. Fig. 1 shows a scheme for such installation. It is composed basically for an expansion tank, a pump, a heater, a set of three-way valves, the instrumentation and the test section. The loop is connected to the lithium filling by a valve, that connect to the auxiliary systems as well. The expansion tank must be able to take the expected increase in volume of the lithium by thermal expansion. The total lithium inventory of the material

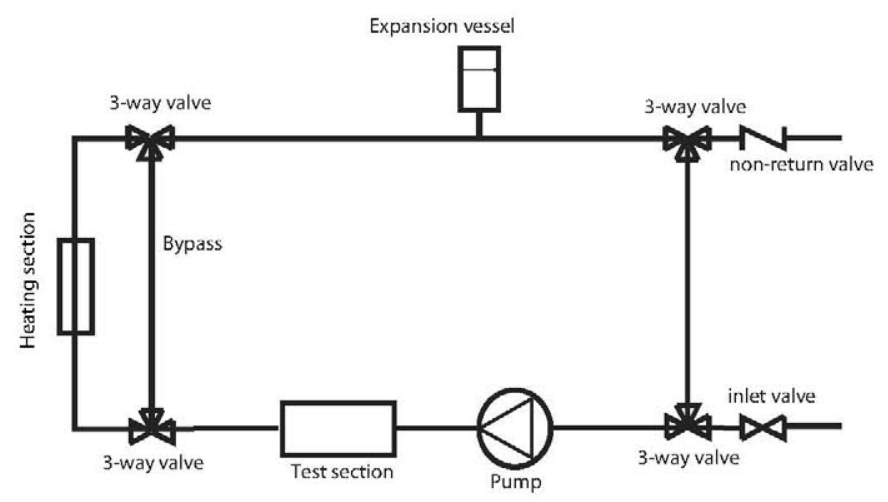

Fig. 1. Scheme of the material testing loop. 
loop is $27 \mathrm{~kg}$, well bellow the $200 \mathrm{~kg}$ that is considered by the Spanish safety guides regarding risky chemical products transportation storage and use [40]. Therefore, we do not expect licensing problems for this first stage for its reduced lithium inventory and radiological risk.

It is planned to allow the material testing under $\gamma$ irradiation from a suitable target in which electrons will impinge from any of the accelerators foreseen in the TECHNOFUSION complex. An hydraulic model has been done to define a preliminary length of the loop (a total duct length of $12.28 \mathrm{~m}$, including bypass and related external connections to filling and auxiliary system), its basic tube diameter ( 0.75 in.) and the pumping required.

The material selection for the loop is based in Stainless Steel 316 in our preliminary design with a maximum temperature of $500^{\circ} \mathrm{C}$. Nevertheless, some work is in progress to asses the definitive loop material in case of upgrading the temperature. The temperature aim of $1000^{\circ} \mathrm{C}$ is very demanding and new material selection could be needed. This temperature aim could also imply the modification of the pumping block, probably with additional cooling and heating sections to operate the pump at lower temperature. The temperature prevention is also applicable to the expansion tank that should not exceed $500^{\circ} \mathrm{C}$.

The temperature control in the loop will be done by an 1$\mathrm{kW}$ electric heater, assuming a nominal operation temperature of $500^{\circ} \mathrm{C}$

\subsection{Free surface loop}

The free surface loop is foreseen to be coupled to an electron accelerator. The impinging of the electrons in the free surface lithium target is intended to produce a heat deposition comparable to the expected energy deposition on the IFMIF target. The electron accelerator that is proposed is a Rhodotron that could provide a particle intensity of $100 \mathrm{~mA}$ within a beam spot between 2 and $4 \mathrm{~mm}$. The maximum energy is $10 \mathrm{MeV}$, although lower energy electron lines could be extracted. By Monte Carlo techniques it was checked that the energy depositions in the lithium flow with $2-\mathrm{MeV}$ electrons are similar to the $40 \mathrm{MeV}$ deuteron deposition foreseen in IFMIF.

The free surface loop design requires a high lithium inventory of 8641 , what implies to adopt special safety rules. A preliminary design has been done for a temperature operation of $250^{\circ} \mathrm{C}$ in the lithium flow able to get $15 \mathrm{~m} / \mathrm{s}$ at the nozzle of the IFMIF mock-up, that will be couple to the electron beam [41]. Fig. 2 shows the basic scheme of the free surface loop that it is expected to be erected in a

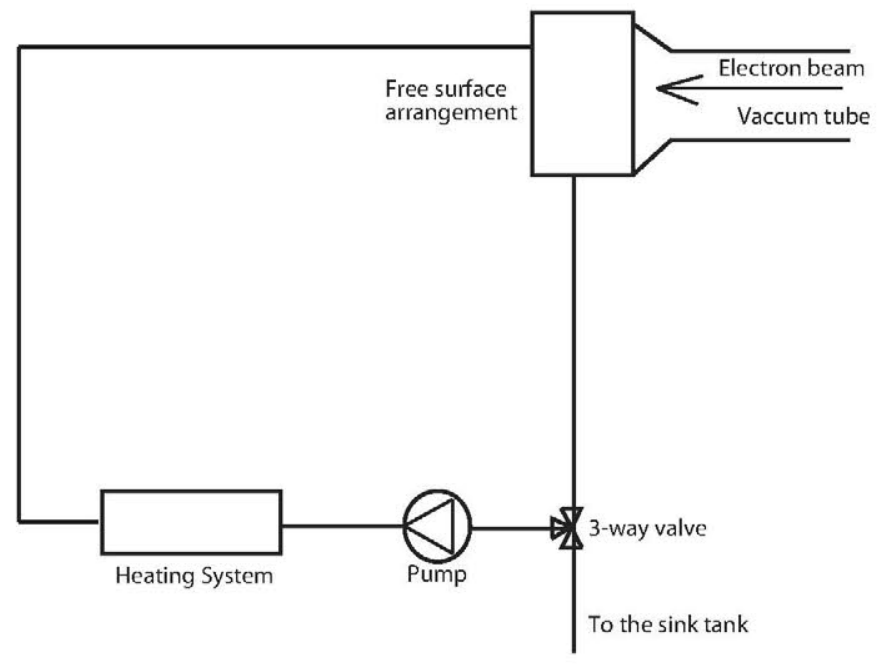

Fig. 2. Scheme of the free surface loop. second stage of the development of the liquid metal laboratory. It is composed of the free surface arrangement, the heating system to keep the temperature around $250^{\circ} \mathrm{C}$, the pump, and the connection to the lithium sink tank. The main difference with other initiatives and experiments available regarding the IFMIF design [42][43], is the possibility to test a mock-up of the IFMIF target with heat generation into the liquid flow, and validate the design that can be done with available engineering tools [44]. This heat generation is produced by the electrons impinging the liquid lithium flow.

This loop has some important characteristics. One of them is the vacuum at the free surface of the liquid metal mock-up of the IFMIF target that is foreseen to be tested. This vacuum will be provided by the connection to the accelerator and it is not included in the specific design of the loop as auxiliary system, but impose a very low pressure boundary condition, as the electron beam should be delivered trough a vacuum tube $\left(10^{-3} \mathrm{~Pa}\right)$. This fact implies that, to keep the hydrostatic pressure at the inlet of the pumping section at a safe level to prevent cavitation, the height difference between the test section and the pumping section should be of the order of $9 \mathrm{~m}$.

\subsection{Auxiliary systems}

The instrumentation and control is one of the practical issues for the construction of the lithium loops that are proposed for the liquid metal laboratory. At the current stage of the development of the project, there is a conceptual design of such loops proposed by IDOM [41] with current state-of-the-art devices, although the development of instrumentation will be one of the objectives of the laboratory, specially when operating at high temperatures.

The composition of the lithium inventory and the impurities contents in the loops are expected to be controlled and kept into certain limits that could comply with quality standards. Such requirement that should be fulfilled by the industrial application of liquid metals implies the development of purification systems. The sources of impurities that can be found in the lithium flow will be the following:

- The delivery impurities, which will depend on the quality of the production system of the lithium provider.

- Diffusion impurities from the structural material that form the circulating loop.

- Impurities from the inert gases that may be used to avoid lithium oxidation.

- Corrosion impurities due to the interaction between the liquid metal and the structural materials.

The impurities may be mostly solid and gaseous. Among the gaseous, oxygen, nitrogen and hydrogen are the most damaging and important impurities. The proposed purification system has the following sections:

- An oxygen and hydrogen extraction system, with high purification efficiency, that should be of the order of $5.5 \mathrm{ppm}$ and $50 \mathrm{ppm}$. respectively.

- A nitrogen extraction system that could reach final concentrations on the lithium flow of the order of 1.6-6 ppm, for instance by aluminium nitrates.

- Solid particle filtering system, to extract the solid impurities, basically coming from corrosion/erosion of the structural materials.

The purification components that might be tested in the laboratory can be classified in two main types: getters and tramps. There is some previous work regarding the IFMIF design [45] The getters are chemical elements that form new compounds with the impurities to be eliminated, that can be separated of the liquid flow by 


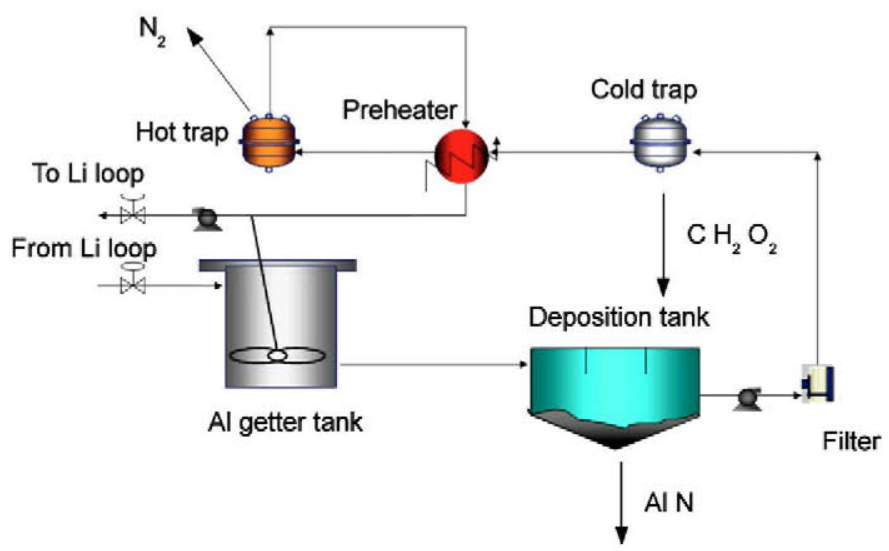

Fig. 3. Scheme of the purification system.

filtering or any physical methods. In most cases, the chemical kinetics should be enhanced with a process at high temperature or flow agitation. Examples of getters are the calcium for oxygen retention, or aluminium for nitrogen.

The cold traps are devices in which the liquid metal is forced to flow trough a structure around $200^{\circ} \mathrm{C}$, that separates physically chemical compounds as oxides, carbides and hydrates. Gaseous impurities, as nitrogen should be separated with warm traps, similar devices operating at $600^{\circ} \mathrm{C}$.

Fig. 3 shows a proposal for the purification system of our loop. In this proposal there is a first stage in which the getter will separate nitrides, oxides and other carbides, with elements as aluminium that will be filtered at the end. A previous section will eliminate the most rough particles from corrosion with a physical mechanical systems. The second stage will be formed by the cold and warm traps that will eliminate the rest of the gaseous impurities as oxygen, nitrogen and hydrogen, that survives the getter section. Our preliminary evaluation of the purification loop dimension leads to approx. $50 \mathrm{~m}$ of 0.5 -in tubes.

Another auxiliary system is the lithium filling system, that is based on the utilization of pressurized Argon bottles that will pump the liquid metal into the loop, and a vacuum system that will be used to avoid liquid metal oxidation.

A complete scheme of the laboratory is shown in Fig. 4.

\section{Economical evaluation}

At this stage of conceptual development, the uncertainties in the economical evaluation are huge, specially because some decision must still be taken that can affect the configuration and lay out of the laboratory. Nevertheless, a preliminary estimation is worthy to evaluate the foreseen order of magnitude of the funding that will be needed for the construction of this laboratory and the whole TECHNOFUSION project.

The preliminary cost of the laboratory has been evaluated in two main aspects: Inversion cost and operation and maintenance cost. The former is the capital cost that will be needed for the construction of the laboratory and the latter is the budget that must be yearly allocated or obtained for the running of the laboratory. As the development of the laboratory is foreseen in two steps, this economic evaluation has been done for the first phase, in which the lithium inventory is limited, the safety requirements are reduced, but keeping the complexity and capacity of the auxiliary systems, that will be common in both cases.

The capital cost includes the experimental loop and the auxiliary equipment, what includes pumps, ducts, valves, and is depicted in Table 2. The total cost has been evaluated in $4.3 \mathrm{M} €$, with near $2 \mathrm{M} €$

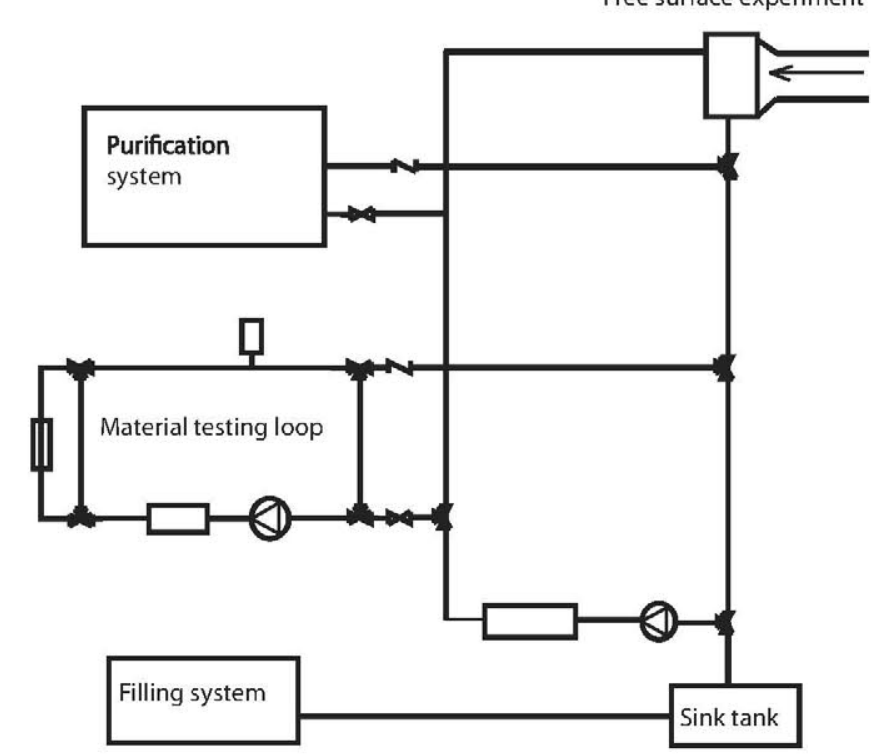

Fig. 4. Scheme of the full integrated liquid metal laboratory.

Table 2

Capital cost for the first phase of the liquid metal laboratory development at the conceptual design stage.

\begin{tabular}{lc}
\hline Item & Cost $(\mathrm{k} €)$ \\
\hline Engineering & 390 \\
Material loop & 1300 \\
Laboratory building & 1800 \\
Project management & 500 \\
Contingencies & 300 \\
Total & 4290 \\
\hline
\end{tabular}

devoted to non-scientific structures, as it is foreseen to commission the laboratory in a new site. The second phase capital cost has been evaluated in $780 \mathrm{k} €$, with the experimental free surface loop and the licensing studies as main items.

The operation and maintenance cost has been evaluated as $640 \mathrm{k} €$, with a personal cost of $350 \mathrm{k} €$ and $100 \mathrm{k} €$ of energy consumption.

\section{Conclusion}

The rationale and the conceptual description of the liquid metal laboratory that is proposed in Spain in the framework of the TECHNOFUSION facility has been presented. This conceptual design is the up-to-date starting point for the detailed engineering design that is in progress, under the support of CDTI (The Centre for the Development of Industrial Technology, depending on the Ministry of Science and Innovation of Spain), the Regional Government of Madrid (including the funded project S2009/ENE-1979) and the participation of the engineering company IDOM International, what implies an effective technology transfer from the scientific field that propose the laboratory, to industrial partners.

\section{References}

[1] E. Bogusch, F. Carré, J. Knebel, K. Aoto, Synergies in the design and development of fusion and generation iv fission reactors, in: Proceedings of the Eight International Symposium of Fusion Nuclear Technology - ISFNT-8 SI, Fusion Engineering and Design 83 (7-9) (2008) 936-942.

[2] D. Gorse-Pomonti, V. Russier, Liquid metals for nuclear applications, in: Liquid and Amorphous Metals XII - Proceedings of the 12th International Conference on Liquid and Amorphous Metals, Journal of Non-Crystalline Solids 353 (32-40) (2007) 3600-3614. 
[3] H. Horiike, S. Konishi, H. Kondo, A. Yamaguchi, Liquid metal cooling issues fo fusion and fission, in: Proceedings of the Eight International Symposium of Fusion Nuclear Technology - ISFNT-8 SI, Fusion Engineering and Design 83 (7-9) (2008) 943-947.

[4] D. Jiménez-Rey, F. Mota, R. Vila, A. Ibarra, C.J. Ortiz, J. Martínez-Albertos, et al Simulation for evaluation of the multi-ion-irradiation laboratory of technofusión facility and its relevance for fusion applications, Journal of Nuclear Materials, in press.

[5] F. Mota, R. Vila, C. Ortiz, A. Garcia, N. Casal, A. Ibarra, et al., Analysis of displacement damage in materials in nuclear fusion facilities (DEMO, IFMIF and TECHNOFUSION), Fusion Engineering and Design, in press.

[6] A. Ibarra, M. Perlado, R. Aracil, D. Blanco, M. Ferre, I. García-Cortés, et al., Technofusión, a relevant facility for fusion technologies: the remote handling area, in: Proceedings of the Ninth International Symposium on Fusion Nuclear Technology, Fusion Engineering and Design 85 (7-9) (2010) 1659-1663.

[7] S.-Y. Chiba, K. Yuki, H. Hashizume, S. Toda, A. Sagara, Numerical research on heat transfer enhancement for high Prandtl-number fluid, in: Proceedings of the Seventh International Symposium on Fusion Nuclear Technology - ISFNT-7 Part A, Fusion Engineering and Design 81 (1-7) (2006) 513-517.

[10] M. Utili, A. Tincani, A. Aiello, I. Ricapito, G. Coccoluto, The European breeding blanket test facility: an integrated device to test European helium cooled TBMS in view of ITER, in: Proceeding of the 25th Symposium on Fusion Technology (SOFT-25), Fusion Engineering and Design 84 (7-11) (2009) 1881-1886.

[16] A. Moeslang, V. Heinzel, H. Matsui, M. Sugimoto, The IFMIF test facilities design, in: Proceedings of the Seventh International Symposium on Fusion Nuclear Technology - ISFNT-7 Part B, Fusion Engineering and Design 81 (8-14) (2006) 863-871.

[17] S. Gordeev, V. Heinzel, D. Leichtle, A. Moeslang Numerical analysis of free surface instabilities in the IFMIF lithium target, in: Proceedings of the Eight International Symposium of Fusion Nuclear Technology - ISFNT-8 SI, Fusion Engineering and Design 83 (10-12) (2008) 1524-1528.

21] R.W. Moir, Liquid wall inertial fusion energy power plants, Fusion Engineering and Design 32-33 (0) (1996) 93-104.

[22] T. Shikama, R. Knitter, J. Konys, T. Muroga, K. Tsuchiya, A. Moesslang, et al., Status of development of functional materials with perspective on beyond-ITER, in: Proceedings of the Eight International Symposium of Fusion Nuclear Technology - ISFNT-8 SI, Fusion Engineering and Design 83 (7-9) (2008) 976-982.

[23] J. Konys, W. Krauss, N. Holstein, Development of advanced al coating processes for future application as anti-corrosion and t-permeation barriers, in: Proceedings of the Ninth International Symposium on Fusion Nuclear Technology Fusion Engineering and Design 85 (10-12) (2010) 2141-2145.

[24] Y. Chen, O. Huang, S. Gao, Z. Zhu, X. Ling, Y. Song, et al., Corrosion analysis of clam steel in flowing liquid lipb at $480^{\circ}$, in: Proceedings of the Ninth International Symposium on Fusion Nuclear Technology, Fusion Engineering and Design 85 $(10-12)(2010)$ 1909-1912.

[25] A. Ciampichetti, I. Ricapito, A. Aiello, G. Benamati, Water large leaks into liquid $\mathrm{Pb}-17 \mathrm{Li}$ : first experimental results on lifus 5 facility, in: 22nd Symposium on Fusion Technology, Fusion Engineering and Design 69 (1-4) (2003) 563-567.

[26] A. Aiello, L. Bühler, A. Ciampichetti, D. Demange, L. Dörr, J. Freibergs, et al., Mockup testing facilities and qualification strategy for EU ITER TBMS, in: Proceedings of the Ninth International Symposium on Fusion Nuclear Technology, Fusion Engineering and Design $85(10-12)(2010)$ 2012-2021.

[27] A. Aiello, A. Ciampichetti, M. Utili, G. Benamati, Triex facility: an experimenta loop to test tritium extraction systems from lead lithium, in: Proceedings of the 24th Symposium on Fusion Technology - SOFT-24, Fusion Engineering and Design $82(15-24)$ (2007) 2294-2302.

[28] C. Wong, J.-F. Salavy, Y. Kim, I. Kirillov, E.R. Kumar, N. Morley, et al., Overview of liquid metal TBM concepts and programs, in: Proceedings of the Eight International Symposium of Fusion Nuclear Technology - ISFNT-8 SI, Fusion Engineering and Design 83 (7-9) (2008) 850-857.

[29] T. Tanaka, F. Bauer, T. Lutz, J. McDonald, R. Nygren, K. Troncosa, et al., Liquid metal integrated test system (limits), Fusion Engineering and Design 72 (1-3) (2004) 83-92, Special Issue on Innovative High-Power Density Concepts for Fusion Plasma Chambers.
[30] P. Garin, Start of the engineering validation and design phase of IFMIF, in Fusion Reactor Materials, Proceedings of the Thirteenth International Conference on Fusion Reactor Materials, Journal of Nuclear Materials 386-388 (2009) 944-948.

[31] J. Allain, M. Nieto, M. Coventry, R. Stubbers, D. Ruzic, Studies of liquid-metal erosion and free surface flowing liquid lithium retention of helium at the University of Illinois, Fusion Engineering and Design 72 (1-3) (2004) 93-110, Special Issue on Innovative High-Power Density Concepts for Fusion Plasma Chambers.

[32] V. Surla, M. Jaworski, T. Gray, K. Ibano, W. Xu, M. Neumann, et al., Lithium research as a plasma facing component material at the University of Illinois, in: Proceedings of the 2nd International Conference on Microelectronics and Plasma Technology - ICMAP 2009, Thin Solid Films 518 (22)(2010)6663-6666.

[33] H. Kondo, A. Fujisato, N. Yamaoka, S. Inoue, S. Miyamoto, T. Iida, et al, Experimental study of lithium free-surface flow for IFMIF target design, in: Proceedings of the Seventh International Symposium on Fusion Nuclear Technology - ISFNT-7 Part A, Fusion Engineering and Design 81 (1-7) (2006) 687-693.

[34] R. Kurtz, A. Alamo, E. Lucon, O. Huang, S. Jitsukawa, A. Kimura, et al., Recent progress toward development of reduced activation ferritic/martensitic steels for fusion structural applications, in: Fusion Reactor Materials, Proceedings of the Thirteenth International Conference on Fusion Reactor Materials, Journal of Nuclear Materials 386-388 (2009) 411-417.

[35] B. Pint, S. Pawel, M. Howell, J. Moser, G. Garner, M. Santella, et al., Initial characterization of $\mathrm{v}-4 \mathrm{cr}-4 \mathrm{ti}$ and mhd coatings exposed to flowing $\mathrm{Li}$, in: Fusion Reactor Materials, Proceedings of the Thirteenth International Conference on Fusion Reactor Materials, Journal of Nuclear Materials 386-388(2009) $712-715$

[36] T. Muroga, B. Pint, Progress in the development of insulator coating for liquid lithium blankets, in: Proceedings of the Ninth International Symposium on Fusion Nuclear Technology, Fusion Engineering and Design 85 (7-9) (2010) 1301-1306.

[37] I. Kupriyanov, V. Kudryavtsev, L. Kurbatova, I. Lyublinski, Effect of high temperature corrosion in liquid lithium on mechanical properties of beryllium, in: Proceedings of the Ninth International Symposium on Fusion Nuclear Technology, Fusion Engineering and Design 85 (7-9) (2010) 1702-1706.

[38] S. Nogami, A. Hasegawa, T. Murayama, N. Otake, M. Satou, K. Abe, Compatibility between sic and Li ceramics for solid breeding blanket system, in: Fusion Reactor Materials, Proceedings of the Thirteenth International Conference on Fusion Reactor Materials, Journal of Nuclear Materials 386-388 (2009) 628-630.

[39] S. Zhao, X. Zhou, H. Yu, H. Wang, Y. Wu, Q. Huang, et al., Compatibility of pip sicf/sic with lipb at $700^{\circ} \mathrm{C}$, in: Proceedings of the Ninth International Symposium on Fusion Nuclear Technology, Fusion Engineering and Design 85 ( 7-9) (2010) 1624-1626.

[40] Guia de sustancias reactivas con el agua - guia 138.

41] IDOM, "Estudio de viabilidad para la integración de dos aceleradores de partículas en el laboratorio de metal líquido de technofusion. memoria técnica proyecto cdti sae-20081014.," tech. rep., 2009.

[42] H. Horiike, M. Ida, T. Iida, S. Inoue, S. Miyamoto, T. Muroga, et al., Lithium free surface flow experiment for IFMIF, in: 22nd Symposium on Fusion Technology, Fusion Engineering and Design 66-68 (0) (2003) 199-204.

[43] T. Furukawa, H. Kondo, Y. Hirakawa, S. Kato, I. Matsushita, M. Ida, et al., Safety concept of the IFMIF/eveda lithium test loop, in: Proceedings of the 26th Symposium of Fusion Technology (SOFT-26), Fusion Engineering and Design 86 (9-11) (2011) 2433-2436.

[44] A Peña, G. Esteban, J. Sancho, V. Kolesnik, A Abanades, Hydraulics and heat transfer in the IFMIF liquid lithium target: CFD calculations, Fusion Engineering and Design 84 (7-11) (2009) 1479-1483.

[45] H. Nakamura, M. Takemura, M. Yamauchi, U. Fischer, M. Ida, S. Mori, et al., Accessibility evaluation of the IFMIF liquid lithium loop considering activated erosion/corrosion materials deposition, Fusion Engineering and Design 75-79 (2005) 1169-1172. 